\title{
Avaliação radiográfica e de função de vôo após fixação de osteotomias distais do úmero em pombas (Columba livia), com modelo de fixador externo articulado ${ }^{1}$
}

\author{
Vanessa C.M. Ferraz ${ }^{2 *}$, Cássio R.A. Ferrigno ${ }^{3}$, Silvia R.G. Cortopassi ${ }^{3}$, \\ Ricardo S. Lopes ${ }^{4}$, Ramiro Isaza ${ }^{5}$ e Stanley Kim ${ }^{6}$
}

\begin{abstract}
Ferraz V.C.M., Ferrigno C.R.A., Cortopassi S.R.G., Lopes R., Isaza R. \& Kim S. 2008. [Radiologic and flight function evaluation after fixation of distal humeral osteotomies in pigeons, with model of articulated external fixator.] Avaliação radiográfica e de função de vôo após fixação de osteotomias distais de úmero em pombas (Columba livia), com modelo de fixador externo articulado. Pesquisa Veterinária Brasileira 28(8):351-357. Departamento de Cirurgia, Faculdade de Medicina Veterinária e Zootecnia, Universidade de São Paulo, Cidade Universitária, Av. Prof. Dr. Orlando Marques de Paiva 87, São Paulo, SP 05508-270, Brazil. E-mail: vanessaferraz@usp.br

The treatment of distal humeral fractures in birds is very difficult, technically and for consolidation and maintenance of normal function of the wing, because theses bones are pneumatic, and its cortices very thin. The ankylosis of the humerus-radius-ulnar joint with external fixator is unviable for birds intended for rehabilitation and release. In all animals, the experimental fixator was placed over the humerus, with its articulation over the humerusradial-ulnar joint e the extension of the fixator was placed over the ulna. The animals were divided in two groups: bilateral surgeries with ankylosis in one wing (static wing) and maintenance of the joint function in the other (dynamic wing) (Group 1), and unilateral surgery, with maintenance of the joint function (dynamic wing) (Group 2). The bonny callus was evaluated with radiographs: post-surgical, at 3, 6 and 9 weeks. The birds in Group 2 were evaluated as of their flight abilities between 11 and 15 weeks after surgery. The wing amplitude and humeral length was evaluated in all animals, after euthanasia. At 6 weeks, all the animals in Group 2, that underwent unilateral surgery, without ankylosis, and four animals in Group 1, that underwent bilateral surgeries: ankylosis of one elbow (static wing) and not of the other (dynamic wing), presented radiographic and clinical consolidation of the fractures. Two animals in Group 1 only presented consolidation of the dynamic wing at 9 weeks and of the static wing at 12 weeks. All the animals in Group 2 presented adequate flight capacity, in at least 13 weeks after surgery. There are few published papers on bird osteosynthesis, and therefore we studied the use of articulated external fixator for the stabilization of distal humeral fractures, avoiding ankylosis of the elbow joint, and, therefore keeping flight function viable, using as a model, rock pigeons (Columba lívia). The proposed method of maintenance of wing function in the dynamic wing, demonstrated being effective in maintaining the length of the bone, the amplitude of the wing as well as viability of muscles and tendons, guaranteeing flight capacity of the studied birds, being a good method for the repair of distal humeral fractures of birds, when rehabilitation and release are intended.
\end{abstract}

INDEX TERMS: Articulated external fixator, birds, humeral fracture.

\footnotetext{
${ }^{1}$ Recebido em 23 de outubro de 2007.

Aceito para publicação em 19 de maio de 2008.

2 Mestrando do Departamento de Cirurgia, Faculdade de Medicina Veterinária, USP, São Paulo, SP. *Autor para correspondência: vanessaferraz@usp.br

${ }^{3}$ Departamento de Cirurgia, Faculdade de Medicina Veterinária e Zootecnia (FMVZ), Universidade de São Paulo (USP), Cidade Universi-
}

\footnotetext{
tária, Av. Prof. Dr. Orlando Marques de Paiva 87, São Paulo, SP 05508270, Brazil.

${ }^{4}$ Graduando, Faculdade de Medicina Veterinária, USP, São Paulo, SP.

${ }^{5}$ College of Veterinary Medicine, University of Florida (UF), SW 16th Ave. 2015, Gainesville, FL 32610, USA.

${ }^{6}$ Small Animal Hospital, UF, SW 16th Ave. 2015 Gainesville, FL 32610, USA.
} 
RESUMO.- O tratamento de fraturas umerais distais em aves impõe grande dificuldade para tratamento e cura, pois estes ossos são pneumáticos, sendo suas córtices muito finas. A anquilose da articulação úmero-rádio-ulnar com fixador externo, é inviável para aves que se pretende a reintrodução ao meio ambiente. Em todas as aves, o fixador experimental foi colocado sobre o úmero, com sua articulação sobre a articulação úmero-rádio-ulnar e a extensão do fixador sobre a ulna. As aves foram divididas em dois grupos: cirurgias bilaterais com anquilose de um lado (asa estática) e manutenção da articulação do outro (asa dinâmica) (Grupo 1), e cirurgia unilateral, com manutenção da articulação (asa dinâmica) (Grupo 2). O calo ósseo foi avaliado através de radiografias pós-cirúrgicas, às 3, 6 e 9 semanas. Os animais do Grupo 2 foram avaliados quanto à capacidade de vôo entre 11 e 15 semanas após a cirurgia. Todos os animais foram avaliados quanto à amplitude da asa e quanto ao comprimento do úmero, após a eutanásia. Às 6 semanas, todos os animais do Grupo 2 e quatro animais do Grupo 1, apresentavam fraturas consolidadas radiografica e clinicamente. Dois animais do Grupo 1 somente apresentaram consolidação das asas dinâmicas às 9 semanas e das estáticas às 12 semanas. Todos os animais do Grupo 2 apresentaram capacidade de vôo adequada, até 13 semanas após a cirurgia. Devido a poucos trabalhos na literatura mundial, o presente trabalho visou o estudo da utilização inédita de fixador externo articulado para a estabilização de fraturas distais de úmero, evitando a anquilose da articulação do cotovelo, e portanto mantendo viável a função de vôo; usando como modelo experimental, pombas (Columba lívia). O método proposto de técnica para fixação de fraturas umerais distais, sem a anquilose da articulação úmero-rádio-ulnar, demonstrou ser efetivo em manter o comprimento ósseo, a amplitude da asa bem como a viabilidade de músculos e tendões, e assim, garantindo a capacidade de vôo das aves tratadas, sendo um método adequado para a reparação de fraturas distais de úmero em aves quando se pretende a reabilitação destes animais.

TERMOS DE INDEXAÇÃO: Fixador externo articulado, aves, fratura umeral.

\section{INTRODUÇÃO}

O processo pelo qual os ossos das aves crescem ou se remodelam, é comumente extrapolado dos conhecimentos que se tem de mamíferos (Tully 2002). As principais diferenças observadas na reparação ortopédica nas aves são o fato de seus ossos apresentarem córtices finos e frágeis, o que resulta em menor fixação óssea de implantes e menos tecidos moles cobrindo os ossos (Helmer \& Redig 2006).

Os ossos apresentam consolidação clínica entre duas e três semanas anteriores à consolidação radiográfica, que ocorre em aproximadamente três a seis semanas. Em pombos, a consolidação de fraturas instáveis foi ca- racterizada por radiolucência aumentada do canal medular e, calo presente histologicamente em nove semanas. A taxa de consolidação depende do deslocamento dos fragmentos, da abrangência da lesão vascular, da presença de agentes infecciosos e da mobilidade da fratura (Withrow 1982, Martin \& Ritchie 1994).

Técnicas de fixação pouco rígidas, como o uso de talas e pinos podem evitar o movimento da articulação, além da necessidade de imobilização prolongada, possíveis hematomas e de causarem formação de calo ósseo exuberante que pode resultar em aderências musculares, atrofia e anquilose da articulação, impedindo a movimentação da asa (Bush 1977, Withrow 1982).

Os fixadores externos promovem calo endostal, devem ser unipolares e colocados em posição dorsal/lateral quando usados no úmero. Não devem interferir na amplitude do movimento das articulações, mantendo assim função da asa e comprimento do osso. No antebraço, os pinos devem ser posicionados na ulna (Bush 1977, Bush 1983, Tully 2002). Os fixadores geralmente levam à recuperação e reabilitação mais rapidamente que outros métodos (Redig 2000). As desvantagens incluem o peso do aparelho e pinos e barras externos à pele, podendo causar lesões no animal (Withrow 1982, Bush 1983).

No tratamento de fraturas umerais, deve-se ter cautela com possíveis lesões do patágio, pois podem resultar em perfuração ou dilaceração e geralmente estas causam contração da pele, alterando a conformação e restringindo a extensão da asa (Helmer \& Redig 2006).

Exames radiográficos pós-cirúrgicos devem ser realizados a intervalos de duas a quatro semanas. As mudanças observadas nesse exame são a reação periostal, esclerose e aumento da radiodensidade do canal medular (Martin \& Ritchie 1994).

Os objetivos para o sucesso na cirurgia de recuperação de fraturas em aves são; uma fixação rígida, bom alinhamento, ausência de infecção e rápido retorno à função, com tempo mínimo de cirurgia, menor interferência no foco de fratura e um método de fixação tolerado pelo animal (Bush, 1977, MacCoy, 1992). Neste trabalho objetivamos avaliar a viabilidade do uso do modelo inédito de fixador externo articulado para a manutenção da função da asa, em aves com fraturas umerais distais.

\section{MATERIAL E MÉTODOS}

Foram utilizados 12 pombos (Columba livia), adultos, pesando aproximadamente $250 \mathrm{~g}$, tratados preventivamente com Ivermectina a $0,2 \mathrm{mg} / \mathrm{kg}$ por via oral, dose única, um mês antes do início do experimento. Durante o ato cirúrgico estes animais sofreram osteotomias distais do úmero, que foram reduzidas com protótipo de fixador externo articulado experimental.

O fixador externo articulado é constituído de três barras de titânio de $6 \mathrm{~mm}$ de diâmetro, com articulações entre elas, sendo uma maior de $3,5 \mathrm{~cm}$, uma média de $3,0 \mathrm{~cm}$, com cinco e quatro perfurações dorso-ventrais, respectivamente, todas eqüidistantes, com exceção do primeiro e segundo orifícios à partir do dispositivo articular, que se localizam mais próximos entre $\mathrm{si}$, e uma terceira barra menor, de $2,5 \mathrm{~cm}$, apresentando ape- 
nas uma perfuração, articulada entre as duas outras barras. Por estes orifícios foram passados os pinos que se inseriam nos ossos. As barras são unidas por dois dispositivos articulares, que são constituídos por parafuso e rosca que podem ser presos ou afrouxados quando necessários movimentos articulares: o dispositivo articular principal, a ser disposto sobre a articulação úmero-rádio-ulnar, e o dispositivo articular secundário, a ser disposto sobre a ulna, com o intuito de melhor adaptar o fixador às diferentes curvaturas das ulnas das aves estudadas. Além disto, exatamente à altura das perfurações, há furos com rosca, por onde são passados parafusos que fixam os pinos ao fixador. Foram utilizados pinos de Shunz de $1 \mathrm{~mm} e$ $1,5 \mathrm{~mm}$, determinados o melhor diâmetro para cada porção do osso de cada animal após a observação do exame radiográfico prévio à cirurgia (Fig.1)

O peso total do fixador articulado é de $9,5 \mathrm{~g}$ e o peso do fixador com os pinos já cortados, à semelhança aos que foram utilizados nas aves, é de $14,0 \mathrm{~g}$

\section{Técnica cirúrgica e anestésica}

A técnica anestésica utilizada incluiu pré-anestesia com butorfanol intra-muscular: 2,0mg/kg, e após 15-20min foi feita a indução com quetamina intra-muscular: $20 \mathrm{mg} / \mathrm{kg}$, e para a manutenção foi utilizado Isofluorano Analgesia no pósoperatório imediato foi realizada com carprofeno intra-muscular: $5 \mathrm{mg} / \mathrm{kg}$. Dipirona sódica, a 1 gota por via oral, durante os três dias consecutivos à cirurgia.

Foram realizados procedimentos cirúrgicos em ambas as asas dos animais do Grupo 1, sendo que uma, escolhida aleatoriamente, sofreu anquilose de sua articulação úmero-rádio-ulnar, não se permitindo o movimento da articulação do fixador, sendo esta asa usada como controle, e chamada de "asa estática". À asa contralateral foi permitido o movimento da peça articular do fixador para impedir a anquilose articular, sendo denominada "asa dinâmica", que foi mantida por três dias após a cirurgia com bandagens em "oito", sendo depois mantida livre até o final do experimento. Os fixadores foram mantidos durante seis semanas ou até a formação de calo ósseo, quando foram retirados

Os animais do Grupo 2 sofreram ato cirúrgico de apenas uma asa, escolhida aleatoriamente, à qual foi permitido o movimento articular, chamada de "asa dinâmica", sendo esta também mantida com bandagem por três dias e depois sendo liberada. Após seis semanas foram retirados os fixadores externos de todos os animais. A outra asa foi denominada de asa intacta.

Após abordagem dorsal do úmero distal, foi realizada osteotomia completa transversal deste, diretamente cranial ao côndilo lateral, a pele foi suturada com náilon 4-0, com padrão simples, separado.

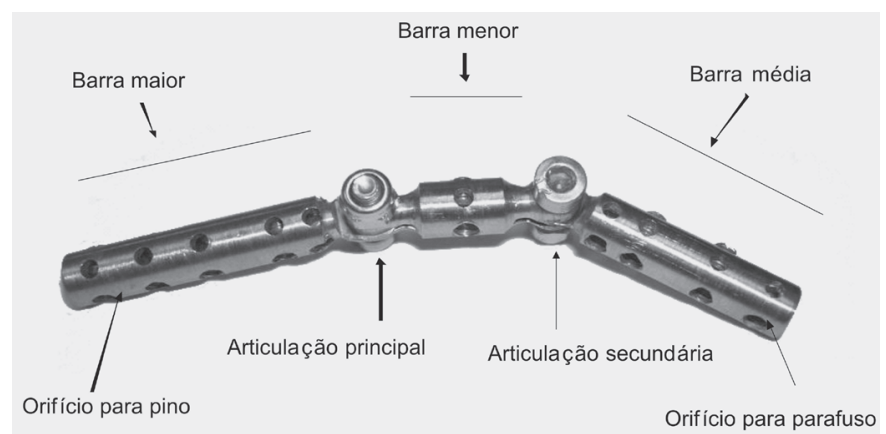

Fig.1. Modelo experimental de fixador articulado.

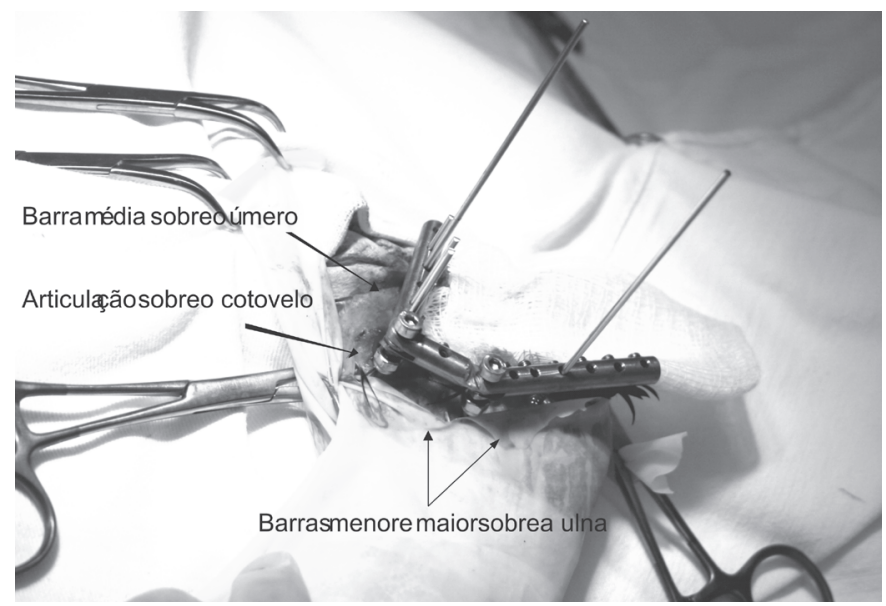

Fig.2. Colocação trans-cirúrgica do fixador.

A barra média do fixador articulado foi posicionada sobre o úmero, alcançando toda sua extensão, com apenas um pino distal à fratura, sobre o côndilo lateral, e dois a três proximais a esta. A barra menor, articulada entre as outras duas, ficou posicionada na parte proximal da ulna, e a barra maior ficou posicionada na extensão distal da ulna, com os pinos passando através das perfurações da barra (Fig.2). Após a cirurgia, foi realizada bandagem em "oito" de modo a manter rígida a articulação da asa estática dos animais, com as barras formando ângulo agudo entre si, aproximando o úmero da ulna de forma anatômica.

A antibioticoterapia preventiva consistiu de amoxicilina, $50 \mathrm{mg}$ oral, a cada vinte e quatro horas, a partir do primeiro dia cirúrgico, e durante os seis dias posteriores, segundo tratamento indicado por Pollock et al. (2005).

\section{Avaliação radiográfica}

Foi realizada avaliação radiográfica no pré e pós-cirúrgico imediato (Fig.3). Às 3, 6, (Fig.4) e 9 semanas pós-operatórias, foram realizadas novas radiografias das asas operadas, para avaliação do calo ósseo, bem como das articulações, para tanto foi utilizada a seguinte técnica radiográfica:

$\mathrm{kV}=35, \mathrm{~mA}=100$, distância $=90 \mathrm{~cm}$, tempo de exposição $=0,016 \mathrm{~s}$; As posições avaliadas foram: dorso-ventral e caudo-cranial.

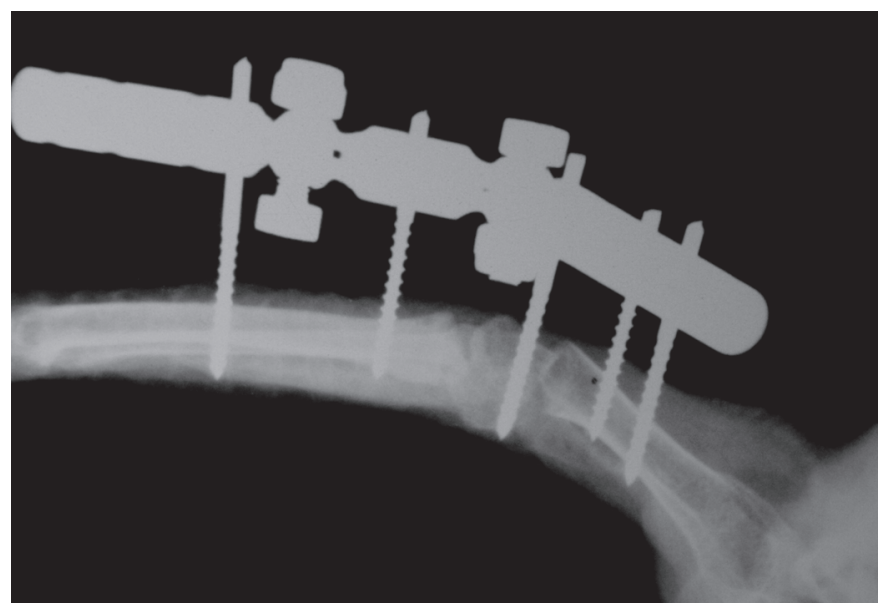

Fig.3. Exame radiográfico de pós-cirúrgico imediato de asa dinâmica (Pombo 1, Grupo 2). 


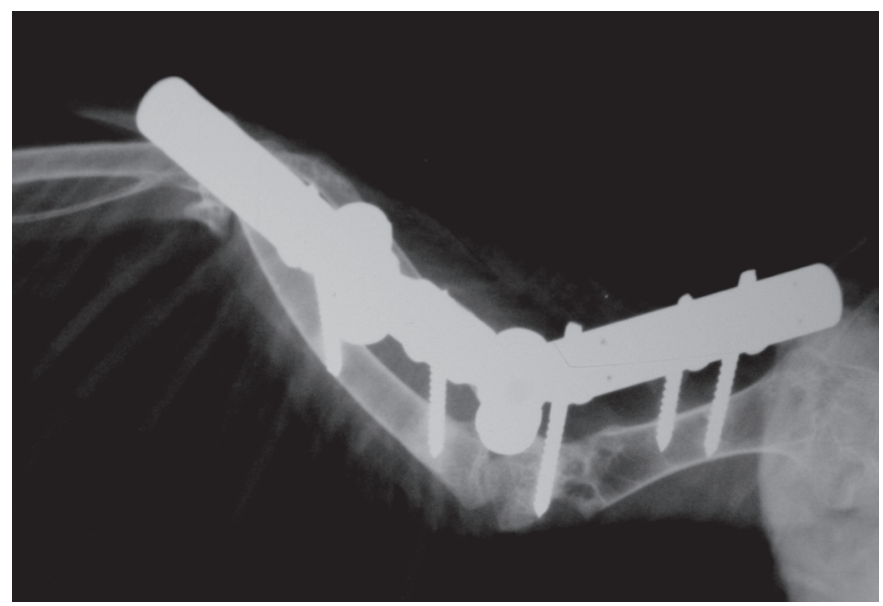

Fig.4. Exame radiográfico da asa dinâmica, seis semanas após a cirurgia (Pombo 1, Grupo 2).

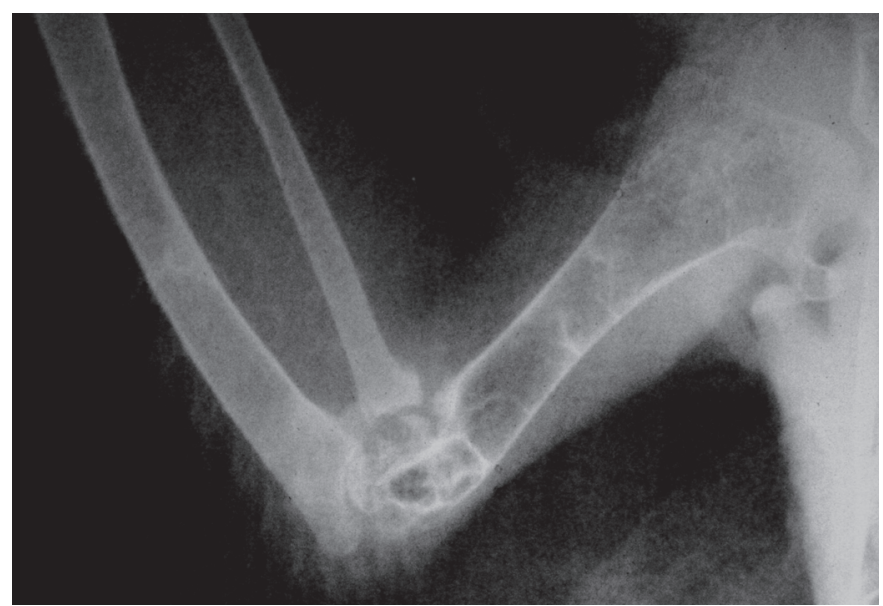

Fig.5. Exame radiográfico de asa dinâmica, à eutanásia (Pombo 1, Grupo 2).

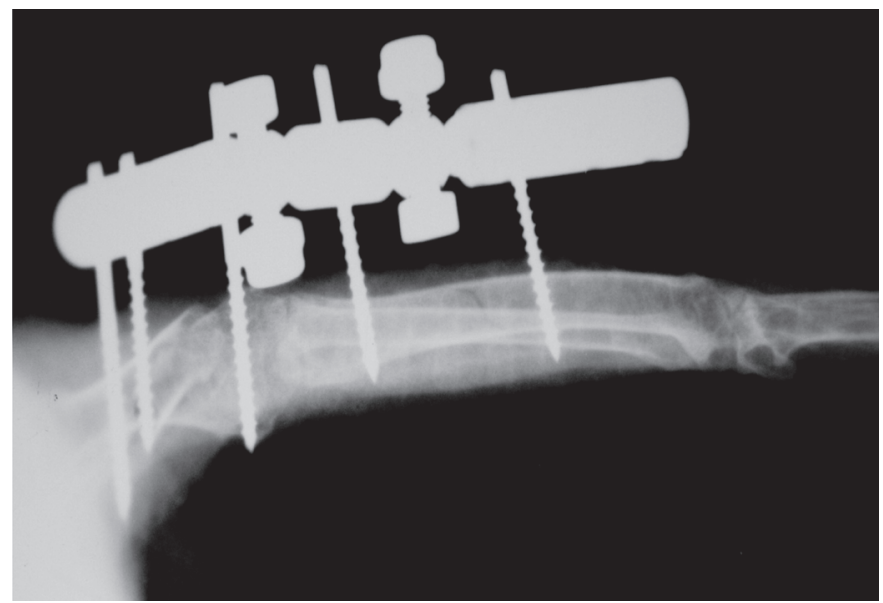

Fig.6. Exame radiográfico, asa estática, imediatamente após a cirurgia (Pombo 2, Grupo 1).

A análise da imagem radiográfica foi feita sob critério padronizado, pelo mesmo operador, considerando-se os seguintes parâmetros: tempo e intensidade da reação periostal, pre-

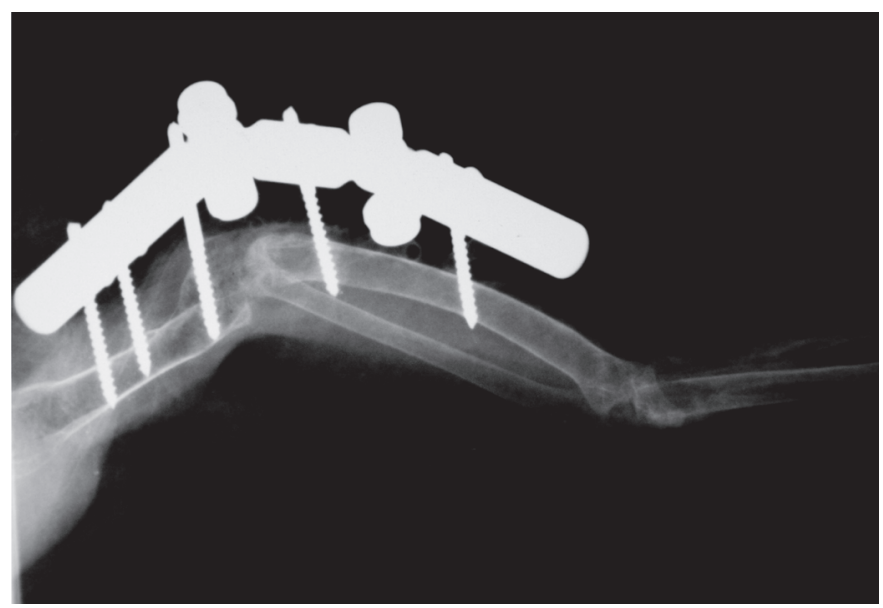

Fig.7. Exame radiográfico de asa estática, seis semanas após a cirurgia (Pombo 2, Grupo 1).

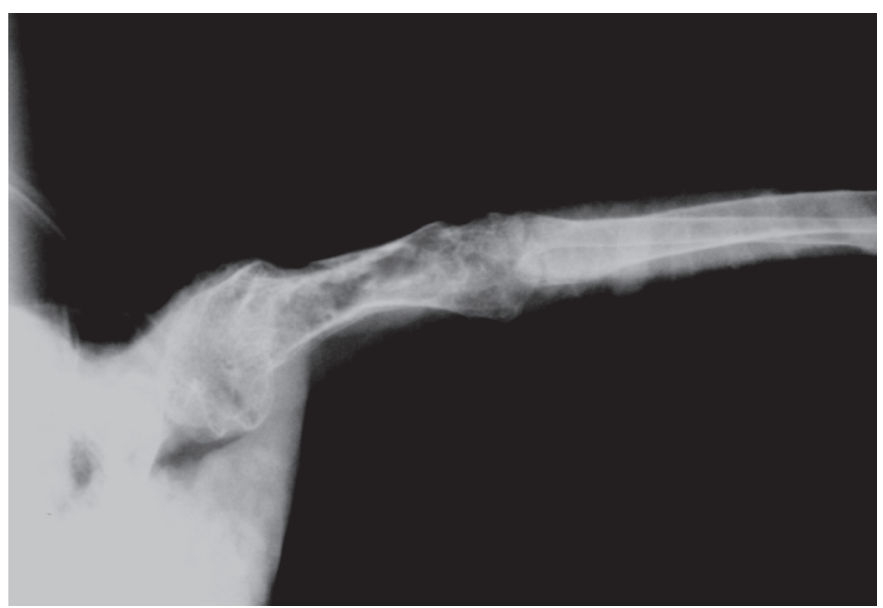

Fig.8. Exame radiográfico de asa estática, à eutanásia (Pombo 2, Grupo 1).

sença ou ausência de calo ósseo e radiotransparência na falha entre os fragmentos.

Foi utilizada classificação qualitativa de acordo com a evolução da consolidação óssea, considerando-se a seguinte adaptação da escala estabelecida por Silva (1998), mais adequada para o tempo de consolidação óssea em aves:

1. Fratura completa com irregularidade nas linhas dos fragmentos;

2. Ponte cortical/ linha radiotransparente na falha entre os fragmentos:

3. Ponte cortical completa / sem linha radiotransparente;

4. Início de remodelação.

\section{Avaliação clínica}

Os pombos foram observados diariamente, porém evitouse sua manipulação excessiva. Quando foi observada a consolidação radiológica das fraturas, após seis semanas, o fixador articulado foi removido, sem remoção dos pinos, para avaliação clínica da fratura, realizada através de palpação. Neste momento o fixador poderia ser reposicionado se necessário, ou retirado por completo, em caso de consolidação clínica.

Tanto antes da cirurgia como após a eutanásia, as asas de 
todos os animais de ambos os grupos foram avaliadas quanto à amplitude de movimento, através do uso de goniômetro, medindose da articulação carpo-rádio-ulnar até a articulação escápuloumeral. Após a eutanásia, os úmeros foram dissecados e medidos quanto ao seu comprimento; da porção mais proximal da articulação da cabeça do úmero, até o côndilo distal.

\section{Avaliação da função}

Os pombos do Grupo 2 foram avaliados quanto à sua capacidade de vôo, sendo que após a retirada do fixador permaneceram em gaiola por cinco semanas, quando foram então deixados em sala de 2,5×2,5×3,0m, com livre acesso às gaiolas, posicionadas tanto no chão quanto em diferentes alturas, até $2 \mathrm{~m}$ e alimentação foi oferecida em diversas alturas, estimulando os animais a exercitarem sua capacidade de vôo em seu próprio tempo. Permaneceram livres na sala por 4 semanas, sendo avaliados neste tempo.

\section{Estatística}

Foi usado o teste $t$-student duplo para determinar a relação da amplitude entre ambas as asas em cada animal, e a relação do comprimento de ambos os úmeros em cada animal.

\section{Comissão de ética \\ O trabalho foi aceito pela comissão de ética da FMVZ, USP (Protocolo 889/2006).}

\section{RESULTADOS}

As asas de todas as aves estavam firmes à palpação após a cirurgia e durante todo o tempo que estas permaneceram com o fixador, com avaliações diárias nos primeiros 7 dias e depois, avaliações a cada 5 dias. $\mathrm{O}$ aparelho não pareceu incomodá-las, e todos os animais foram capazes de suportar o peso do aparato, apresentando leve queda da asa no início, que melhorou gradualmente durante as semanas do experimento.

Por diversas vezes não foi possível restringir a osteotomia a uma fratura transversa simples devido ao caráter frágil e delgado da cortical deste osso nas aves, sendo que em alguns casos (2 animais do Grupo 1) a fratura apresentou bisel em sua formação. No Pombo 4 do Grupo 1, observou-se fissura longitudinal do úmero, que aos 21 dias havia aumentado consideravelmente de tamanho, provocando separação parcial das duas corticais deste osso. Não obstante, às 6 semanas ocorreu consolidação completa do osso, apesar desta complicação. No Pombo 3 do Grupo 2 a fratura não apresentou alinhamento completo após a cirurgia.

Durante a cirurgia ocorreram fraturas iatrogênicas nas ulnas de 5 animais do Grupo 1, quando da inserção dos pinos, o que foi confirmado posteriormente no exame radiográfico pós-cirúrgico imediato. Nenhuma fratura foi observada nas ulnas dos animais do Grupo 2.

A avaliação radiográfica de todos os animais, segundo tabela adaptada de Silva (1998) está nos Quadros 1 e 2. Metade dos animais do Grupo 1 apresentou consolidação completa da asa estática em 21 dias, e um animal apresentou consolidação completa da asa dinâmica neste período. Às 6 semanas, quatro animais do Grupo 1
Quadro 1. Avaliação radiográfica dos animais do Grupo 1, segundo escala adaptado de Silva (1998)

\begin{tabular}{ccccccc}
\hline Pombo & Pós $^{\text {a }}$ & 21dias & $\begin{array}{c}6 \text { se- } \\
\text { manas }\end{array}$ & $\begin{array}{c}9 \text { se- } \\
\text { manas }\end{array}$ & $\begin{array}{c}12 \text { se- } \\
\text { manas }\end{array}$ & $\begin{array}{c}15 \text { se } \\
\text { mana }\end{array}$ \\
$\begin{array}{c}1 \\
\text { Asa dinâmica }\end{array}$ & $1 \#$ & 2 & 3 & 3 & - & - \\
$\begin{array}{c}\text { Asa estática } \\
2\end{array}$ & $1 \#$ & 2 & 2 & 3 & 3 & 3 \\
$\begin{array}{c}\text { Asa dinâmica } \\
\text { asa estática }\end{array}$ & 1 & 2 & 3 & 4 & - & - \\
3 & 3 & 3 & 4 & - & - \\
$\begin{array}{c}\text { Asa dinâmica } \\
\text { Asa estática }\end{array}$ & 1 & 2 & 3 & 4 & - & - \\
4 & 3 & 3 & 4 & - & - \\
$\begin{array}{c}\text { Asa dinâmica } \\
\text { Asa estática }\end{array}$ & $1 \#$ & 3 & 3 & 4 & - & - \\
5 & 2 & 2 & 2 & 2 & 3 \\
$\begin{array}{c}\text { Asa dinâmica } \\
\text { Asa estática }\end{array}$ & 1 & 2 & 3 & 4 & - & - \\
6 & 2 & 3 & 4 & - & - \\
Asa dinâmica & 1 & 2 & 4 & 4 & - & - \\
Asa estática & 1 & 3 & 4 & 4 & - & - \\
\hline
\end{tabular}

a \# = fraturas iatrogênicas do úmero ou da ulna.

Quadro 2. Avaliação radiográfica dos animais do Grupo 2 segundo escala adaptado de Silva (1998)

\begin{tabular}{cccccc}
\hline Pombo Pós & 21dias & $\begin{array}{c}6 \text { se- } \\
\text { manas }\end{array}$ & $\begin{array}{c}9 \text { se- } \\
\text { manas }\end{array}$ & $\begin{array}{c}12 \text { se- } \\
\text { manas }\end{array}$ & $\begin{array}{c}15 \mathrm{se}- \\
\text { manas }\end{array}$ \\
\hline
\end{tabular}

1

$\begin{array}{ccccc}\begin{array}{c}\text { Asa dinâmica } \\ \text { Asa intacta }\end{array} & 1 & 3 & 3 & 4 \\ \begin{array}{c}2 \\ \text { Assa dinâmica } \\ \text { Asa intacta } \\ \quad 1\end{array} & 1 & 2 & 3 & 4 \\ \begin{array}{c}\text { Asa dinâmica } \\ \text { Asa intacta } \\ \quad\end{array} & 1 & 2 & 3 & 4 \\ \begin{array}{c}\text { Asa dinâmica } \\ \text { Asa intacta } \\ \quad 5\end{array} & 1 & 3 & 3 & 4 \\ \begin{array}{c}\text { Asa dinâmica } \\ \text { Asa intacta } \\ \quad 6\end{array} & 1 & 2 & 3 & 4 \\ \text { Assa dinâmica } & 1 & 3 & 3 & 4 \\ \text { Asa intacta } & & & & \end{array}$

apresentaram consolidação radiográfica e clínica, de ambas as asas, quando foram retirados os fixadores.

Dois animais do Grupo 1 apresentaram consolidação radiográfica, porém não clínica da asa dinâmica e não apresentaram consolidação da asa estática às 6 semanas. Às 9 semanas ambos apresentaram consolidação clínica da asa dinâmica e estes fixadores foram retirados, e apresentaram consolidação radiográfica porém não clínica da asa estática, e foram mantidos os fixadores das asas estáticas até as 12 semanas, quando apresentaram consolidação clínica destas e os fixadores foram retirados. Às 15 semanas estes animais foram eutanasiados, sendo que um deles apresentou mal-união hipertrófica da asa estática, segundo classificação de Martin \& Ritchie (1994) e Helmer \& Redig (2006). 
Com exceção destes dois animais, as aves do Grupo 1 foram eutanasiadas às 9 semanas, após 3 semanas da retirada dos fixadores.

Após a retirada dos fixadores às 6 semanas, os animais do grupo 2 foram mantidos em gaiola por 5 semanas, quando foram soltos em sala, para o vôo. Foram mantidos assim por 4 semanas antes de serem eutanasi-

Quadro 3. Comprimento do osso, relação entre comprimento de asa dinâmica e asa estática no Grupo 1. Amplitude da asa, medida da parte mais proximal do úmero até a parte mais distal da ulna, em linha reta, e a relação entre amplitude da asa dinâmica e asa estática

\begin{tabular}{|c|c|c|c|c|}
\hline Pombo & $\begin{array}{l}\text { Comprimento } \\
\text { do osso }(\mathrm{cm})\end{array}$ & Relação & $\begin{array}{c}\text { Amplitude } \\
\text { da asa }(\mathrm{cm})\end{array}$ & Relaçã \\
\hline 1 & & & & \\
\hline Asa dinâmica & 4,9 & & 7,1 & \\
\hline $\begin{array}{c}\text { Asa estática } \\
2\end{array}$ & 4,9 & 1 & 6,8 & 1,04 \\
\hline Asa dinâmica & 4,6 & & 6,4 & \\
\hline $\begin{array}{c}\text { Asa estática } \\
3\end{array}$ & 4,4 & 1,0454 & 7,2 & 0,89 \\
\hline Asa dinâmica & 4,4 & & 7,5 & \\
\hline $\begin{array}{c}\text { Asa estática } \\
4\end{array}$ & 4,2 & 1,0476 & 6,5 & 1,15 \\
\hline Asa dinâmica & 4,5 & & 6,7 & \\
\hline $\begin{array}{c}\text { Asa estática } \\
5\end{array}$ & 4,9 & 0,9183 & 6,5 & 1,03 \\
\hline Asa dinâmica & 4,4 & & 6,8 & \\
\hline $\begin{array}{c}\text { Asa estática } \\
6\end{array}$ & 4,6 & 0,9565 & 8 & 0,85 \\
\hline Asa dinâmica & 4,5 & & 8,3 & \\
\hline Asa estática & $\begin{array}{c}4,6 \\
4,55\end{array}$ & 0,9782 & $\begin{array}{c}6,1 \\
7,1333\end{array}$ & 1,36 \\
\hline Média & 4,6 & 0,991 & 6,85 & 1,05 \\
\hline
\end{tabular}

Quadro 4. Comprimento do osso, relação entre comprimento de asa dinâmica e asa intacta, no Grupo 2. Amplitude da asa, medida da parte mais proximal do úmero até a parte mais distal da ulna, em linha reta, e a relação entre amplitude da asa dinâmica e asa intacta

\begin{tabular}{|c|c|c|c|c|}
\hline Pombo & $\begin{array}{l}\text { Comprimento } \\
\text { do osso }(\mathrm{cm})\end{array}$ & Relação & $\begin{array}{c}\text { Amplitude } \\
\text { da asa }(\mathrm{cm})\end{array}$ & Relação \\
\hline 1 & & & & \\
\hline Asa dinâmica & 4,5 & & 6 & \\
\hline $\begin{array}{c}\text { Asa intacta } \\
2\end{array}$ & 4,5 & 1 & 7 & 0,86 \\
\hline Asa dinâmica & 4,75 & & 8 & \\
\hline $\begin{array}{c}\text { Asa intacta } \\
3\end{array}$ & 4,7 & 1,0106 & 8,4 & 0,95 \\
\hline Asa dinâmica & 4,4 & & 8,2 & \\
\hline $\begin{array}{c}\text { Asa intacta } \\
4\end{array}$ & 4,5 & 0,9777 & 6,9 & 1,19 \\
\hline Asa dinâmica & 4,5 & & 5 & \\
\hline $\begin{array}{c}\text { Asa intacta } \\
5\end{array}$ & 4,6 & 0,9782 & 6 & 0,83 \\
\hline Asa dinâmica & 4,9 & & 6,6 & \\
\hline $\begin{array}{c}\text { Asa intacta } \\
6\end{array}$ & 4,7 & 1,0425 & 8,3 & 0,8 \\
\hline Asa dinâmica & 4,9 & & 7,7 & \\
\hline Asa intacta & $\begin{array}{c}4,7 \\
4,658\end{array}$ & 1,0425 & $\begin{array}{c}8,3 \\
6,9166\end{array}$ & 0,93 \\
\hline Média & 4,616 & 1,0086 & 7,3928 & 0,93 \\
\hline
\end{tabular}

ados. Todos os animais deste grupo apresentaram capacidade de vôo adequada, levantando vôo até $2 \mathrm{~m}$ de altura, sendo capazes de subir e descer a diferentes alturas, após o quinto dia que foram liberados na sala, melhorando rapidamente seu equilíbrio e destreza no vôo.

O comprimento dos úmeros dos animais do Grupo 1 não apresentou variação entre a asa dinâmica e a asa estática $(P=0,624)$, nem a amplitude das asas destes animais demonstrou diferença $(P=0,597)$.

As asas dinâmicas e intactas dos animais do Grupo 2 também não apresentaram variação entre si, em relação ao comprimento dos úmeros ( $\mathrm{P}=0,681)$, ou amplitude da asa $(P=0,231)$. Os comprimentos dos úmeros, bem como as relações entre ambos os úmeros de cada animal, assim como as amplitudes de asa e a relação entre as amplitudes de cada asa de um mesmo animal, estão relacionadas nos Quadros 3 e 4.

\section{DISCUSSÃO}

O uso do fixador articulado levou à consolidação de todos os ossos, tanto das asas dinâmicas quanto das estáticas de todas as aves de ambos os grupos. Às 6 semanas, todos os pombos do Grupo 2 apresentavam fraturas consolidadas radiografica e clinicamente, sendo os fixadores removidos por completo neste momento.

O principal calo ósseo nas aves é intramedular, e este provê um suporte rápido e rígido, em fratura bem alinhada e estável, o que dificultou a classificação radiográfica das fraturas, pois este calo é de difícil visualização, enquanto o calo ósseo periostal provê um suporte secundário e não é tão extenso quanto o anterior, e não foi visualizado em nenhuma radiografia.

O tempo de consolidação das asas dinâmicas de ambos os grupos foi relativamente rápido para o nível de estabilidade, considerado baixo, causado pelo fixador articular, sendo que este somente apresentava um pino distal à fratura, no úmero. Bush (1977) e Martin \& Ritchie (1994) consideram 3-8 semanas o tempo normal para consolidação de fraturas bem alinhadas e com fixação rígida, sendo 9 semanas o tempo esperado para a consolidação de fraturas com baixa estabilidade em pombos.

Ocorreram fraturas iatrogênicas nas ulnas de 5 pombos do Grupo 1, como demonstrado no Quadro 1, provavelmente porque os pinos rosqueados eram de tamanho adequado para o úmero, porém talvez um pouco grandes para a ulna, que em alguns animais apresentava diâmetro menor do que na média. Devido à seleção aleatória das asas, estas fraturas não foram relacionadas a um único tipo de fixação, não parecendo influenciar diretamente nos resultados. Todas as ulnas que sofreram fraturas iatrogênicas consolidaram antes dos úmeros (aprox. 21 dias após a cirurgia).

A utilização de pinos semi-rosqueados garantiu a não soltura dos mesmos (Coles 1996).

A liberação dos pombos do Grupo 2 em sala durante 5 semanas, permitindo o vôo segundo a capacidade de cada animal, demonstrou ser uma alternativa adequada para a 
reabilitação física proposta por Martin \& Ritchie (1994), com aumentos progressivos na amplitude de movimento e exercícios, já que adesões de ligamentos e tendões podem causar limitação do vôo, mesmo quando a fratura se resolveu por completo, o quê ocorre principalmente quando as articulações são imobilizadas por períodos prolongados (Withrow 1982, Helmer \& Redig 2006). Isto permitiu movimentação livre das asas e ao mesmo tempo evitou o estresse da contenção mecânica e da fisioterapia passiva, além de respeitar o tempo de retorno à função da asa de cada ave. A reabilitação pós-operatória é vital para garantir a re-vascularização local, melhorando tecidos lesados e a consolidação óssea, sendo que técnicas ativas e passivas de reabilitação devem ser utilizadas assim que possível após a cirurgia (Martin \& Ritchie 1994).

Os comprimentos dos úmeros da asa dinâmica e da asa estática de cada ave do Grupo 1 foram comparados, sendo que a asa dinâmica apresentou em média, 99,1\% do tamanho da asa estática em cada ave. A mesma análise foi feita para os animais do Grupo 2, e as asas dinâmicas representavam em média $99,5 \%$ do tamanho dos úmeros das asas intactas. Pode-se afirmar que o método de fixação proposto garante o alinhamento anatômico proposto como fundamental por Helmer \& Redig (2006), mantendo comprimento mínimo adequado do úmero, demonstrando que a técnica de fixação articulada é viável em comparação à técnica clássica de anquilose da articulação e mesmo mantendo proporções anatômicas quando comparada à anatomia normal da asa.

A amplitude da asa, no Grupo 2, demonstrou que a relação da asa operada para a asa intacta foi de $93 \%$, denotando uma capacidade reduzida de movimento da articulação, possivelmente devido à inflamação e alterações degenerativas da articulação, causadas pela estabilização instável da fratura. Os animais provavelmente apresentariam capacidade adequada de vôo em condições naturais, porém não há trabalhos que comprovem a amplitude mínima de asa adequada para o vôo. Nenhum pombo do Grupo 2 apresentou recolhimento completo da asa operada, porém eram capazes de apresentar postura ereta, bom equilíbrio e recolhimento parcial a quase total da asa, e ao final do experimento, todos apresentaram capacidade de vôo adequada, em ambiente controlado.

O mesmo valor foi calculado para o Grupo 1, e neste pudemos notar que a relação foi de $105 \%$, o que era esperado pois as asas estáticas sofreram anquilose parcial de sua articulação inabilitando-as de movimento amplo, porém não restringindo totalmente o movimento. Durante todo o experimento foi possível observar que os pombos do Grupo 1 apresentavam dificuldade e dor na movimentação da asa estática, nunca sendo capazes de recolhêla junto ao corpo, mostrando-se desequilibrados, e em dois casos, arrastando a asa junto ao solo.

Estatisticamente a amplitude de asa dos pombos do Grupo 2 foi adequada quando comparamos a asa dinâmica à asa intacta, e pode-se dizer que a técnica proposta é eficiente em manter amplitude adequada de asa, sendo possível o vôo em ambiente controlado. Mais estudos são necessários para determinar se a técnica garante a reabilitação total do animal, garantindo situação adequada para a liberação na natureza.

A opção pelo uso de fixador externo foi adequada, garantindo pequeno tempo cirúrgico, não necessitando de um segundo ato cirúrgico para sua remoção, além de demonstrar-se ser um implante de baixo peso total, aproximadamente $7 \%$ do peso do animal, vantagens apontadas por Bush (1983).

Agradecimentos.- À Fundação de Amparo à Pesquisa do Estado de São Paulo-FAPESP, pelo financiamento do projeto.

\section{CONCLUSÃO}

O método de manutenção da função da asa, utilizandose modelo inédito de fixador articulado, na asa dinâmica, demonstrou ser efetivo em manter o comprimento ósseo, a amplitude da asa bem como a viabilidade de músculos e tendões, e assim, garantindo a capacidade de vôo das aves tratadas, sendo um método adequado para a reparação de fraturas distais de úmero em aves quando se pretende a reabilitação destes animais.

\section{REFERÊNCIAS}

Bush M. 1977. External fixation of avian fractures. J. Am. Med. Vet. Assoc. 171(1):943-946.

Bush M. 1983. External fixation to repair long bone fractures in larger birds, p.629-633. In: Kirk R.W. (ed.), Current Veterinary Therapy VIII. W.B. Saunders, Philadelphia.

Coles B.H. 1996. Wing problems, p.34-146. In: Beynon P.H. (ed.), Manual of Psittacine Birds. British Small Animal Veterinary Association, Shurdingtnon.

Degernes L.A., Roe S.C. \& Abrams Jr C.F. 1998. Holding power of different pin designs and pin insertion methods in avian cortical bone. Vet. Surg. 27(4):301-306.

Helmer P. \& Redig P.T. 2006. Surgical resolutions of orthopedic disorders, p.761-774. In: Harrison G.J. \& Lightfoot T.L. (ed.), Clinical Avian Medicine. Vol.2. Spix Publishing Inc., Palm Beach.

Lind P.J., Gushwa D.A. \& Vanek J.A. 1988. Fracture repair in two owls using polypropylene rods and acrylic bone cement. Assoc. Avian Vet. Today 2(3):128-132.

MacCoy D. 1992. Treatment of fractures in avian species. Vet. Clin. North Am., Small Anim. Pract., 22(1):225-238.

Martin H. \& Ritchie B.W. 1999. Orthopedic surgical techniques, p.11371169. In: Ritchie B.W., Harrison G.J. \& Harrison L.R. (ed.), Avian Medicine: Principles and application. Wingers Publishing, Inc., Lake Worth.

Pollock C., Carpenter J.W. \& Antinoff N. 2005. Exotic Animal Formulary. 3rd ed. Elsevier Saunders, Philadelphia, p.131-141.

Redig P. 2000. "Fractures" in Chapter 6, Trauma-related medical conditions. In: Samour J. (ed.), Avian Medicine. Mosby, Philadelphia.

Silva M.F.A. 1998. Efeitos do ultra-som de baixa intensidade sobre a cicatrização óssea de fraturas experimentais produzidas nas fíbulas de cães (Canis familiaris). Tese de Doutorado em Cirurgia, Faculdade de Medicina Veterinária e Zootecnia, USP, São Paulo, SP. 72p.

Tully T.N.Jr 2002. Basic avian bone growth and healing. Vet. Clin. North Am., Anim. Pract. 5(1):23-30.

Withrow S. 1982. General principles of fractures repair in raptors. Comp. Cont. Educ. Pract. Vet. 4(2):116-121. 